\title{
Maxillofacial Fractures: A Three-Year Survey
}

\author{
Oluwafemi Adewale Adesina ${ }^{\mathrm{a}, \mathrm{b}}$, John Chukwudumebi Wemambu ${ }^{\mathrm{a}}$, \\ Taofiq Olamide Opaleye ${ }^{\mathrm{a}}$, Ajibola Yussuf Salami ${ }^{\mathrm{a}}$
}

\begin{abstract}
Background: Maxillofacial fractures constitute a substantial proportion of trauma globally. The main causes worldwide are road traffic accidents (RTAs), falls, assaults, sports, firearm injuries and industrial trauma. The highest incidence is commonly seen in the young age group with majority being male. The most common site in maxillofacial injuries is the mandible followed by the zygomatic complex, maxilla, and alveolar process. Maxillofacial trauma also poses a significant socioeconomic burden on affected individuals. Hence appropriate treatment and prevention of these morbidities and possible mortality is necessary. This study is therefore aimed at analyzing the prevalence, pattern of presentation of maxillofacial injuries at Lagos State University Teaching Hospital (LASUTH) in Western Nigeria.
\end{abstract}

Methods: A retrospective review of 182 patients diagnosed and treated for maxillofacial injuries at the Oral and Maxillofacial Department of the LASUTH was conducted. Data were obtained from clinical notes and records of radiological findings noting patient's age, gender, etiologic factors (RTA, assault, sport, and fall), anatomic site of injury and different definitive treatment modalities. The data were analyzed by SPSS version 20 using various descriptive statistical tools. Mean and standard deviation were calculated for quantitative variable like age while frequency and percentage were calculated for qualitative variables like gender and site of fracture.

Results: Majority of patients were male $(72.0 \%)$ with a male to female ratio of 1:0.4. Most patients were between 31 and 40 (34.1\%) years of age. RTA accounting for $73.1 \%$ of the injuries was the most common cause for maxillofacial injury followed by assault $(19.2 \%)$. Majority of injuries due to RTA were of motorcycles accidents (33.6\%). The most common sites of fracture out of 226 sites were in the mandible $(62.8 \%, \mathrm{P}=0.003)$. Among the mandibular fracture sites, $28.2 \%$ affected the body of the mandible. Majority $(31.9 \%)$ of the studied patients presented within $24 \mathrm{~h}$ ( $\leq 1$ day). Out of the 182 patients, $68.1 \%$ were treated by close reduction.

Manuscript submitted September 9, 2019, accepted November 14, 2019

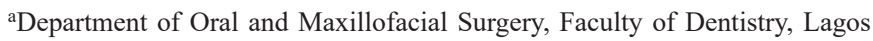
State University College of Medicine, Lagos State, Nigeria

${ }^{\mathrm{b} C}$ Corresponding Author: Oluwafemi Adewale Adesina, Department of Oral and Maxillofacial Surgery, Faculty of Dentistry, Lagos State University College of Medicine, Lagos State, Nigeria.

Email: femmyadesina2000@yahoo.com

doi: https://doi.org/10.14740/jcs387
Conclusions: RTA represented the major etiological factor of maxillofacial injuries. The mandible remains the most affected bone of the facial skeleton. Closed reduction is the most common approach used for treatment.

Keywords: Maxillofacial; Injuries; Survey

\section{Introduction}

Maxillofacial fractures constitute a substantial proportion of trauma globally $[1,2]$. This is due to the vulnerability of the maxillofacial region to injury either in isolation or in combination with other systems because of its exposure [3].

The main causes worldwide are road traffic accidents (RTAs), falls, assaults, sports, firearm injuries and industrial trauma $[4,5]$. However, etiological factors and patterns of maxillofacial injuries reported from different regions at different times are largely influenced by prevailing socioeconomic, cultural, environmental and legislative factors, as well as location of the trauma center $[6,7]$.

The highest incidence is commonly seen in the young age group of 21 - 30 years [8]. Most of the patients are male, with a male to female ratio of approximately $3: 1$ [9]. The most common site in maxillofacial injuries is the mandible followed by the zygomatic complex, maxilla, and alveolar process [4]. Some authors have reported zygoma as a more susceptible bone than the maxilla [10].

Facial bone fractures have high impact on the esthetics and shape of the face, and also causing deformation of growing jaw bones, temporomandibular joint and occlusion disorders, crushing and loss of bones, facial deformity and loss of teeth [11]. Maxillofacial trauma also poses a significant socioeconomic burden on affected individuals [12]. Hence appropriate treatment and prevention of these morbidities and possible mortality is necessary.

It is therefore imperative to study the mechanism of maxillofacial injury, pattern and incidence for appropriate planning and effective management of facial injuries. This study is therefore aimed at analyzing the prevalence, pattern of presentation of maxillofacial injuries in our center which is a major trauma referral center in Western Nigeria.

\section{Materials and Methods}

A retrospective review of patients who had been diagnosed 
Table 1. Age and Gender Distribution

\begin{tabular}{lllll}
\hline Age & Male $(\mathbf{n}=\mathbf{1 3 1})$ & Female $(\mathbf{n}=\mathbf{5 1})$ & Total & P value \\
\hline $0-10$ & $4(3.1)$ & $2(3.9)$ & $6(3.3)$ & 0.894 \\
$11-20$ & $11(8.4)$ & $8(10.4)$ & $19(10.4)$ & 0.493 \\
$21-30$ & $49(37.4)$ & $10(32.4)$ & $69(32.4)$ & 0.392 \\
$31-40$ & $41(31.3)$ & $21(41.2)$ & $22(12.1)$ & 0.201 \\
$41-50$ & $16(12.2)$ & $6(11.8)$ & $11(6.0)$ & 0.588 \\
$51-60$ & $7(5.3)$ & $4(7.8)$ & $3(1.6)$ & 0.594 \\
$>60$ & $3(2.3)$ & $0(0.0)$ & & 0.429 \\
Mean \pm SD & $31.64 \pm 11.9$ & $31.47 \pm 12.3$ & 0.932 \\
\hline
\end{tabular}

$X^{2}=8.144, P=0.228 . S D:$ standard deviation.

and treated for maxillofacial injuries at the Oral and Maxillofacial Department of the Lagos State University Teaching Hospital (LASUTH) was conducted by the authors after securing clearance from the ethical committee. It was a 3-year study conducted from January 2016 to December 2018. LASUTH is a major referral center for trauma cases in the region. These patients had been referred from the oral diagnosis and accident and emergency units of the same hospital.

Data were obtained from patient's clinical case notes and records of radiological findings, the patient's age and gender, etiologic factors (RTA, assault, sport, and fall), anatomic site of injury, and different definitive treatment modalities were recorded. Patients with incomplete records were excluded.

According to the records, facial fractures were classified into midfacial fractures which involved orbit, maxilla (Le Fort I, Le Fort II, Le Fort III, maxillary dentoalveolar process), and zygomatic complex fracture. Mandibular fractures were classified as symphyseal, parasymphyseal, body, angle, condyle, ramus, dentoalveolar, or coronoid fractures.

The time lapse between injury occurrence and presentation for treatment was also categorized into logical groupings for statistical analysis. Day 0 - 1 was regarded as good, and 2 - 7 days as realistic, followed by mild ( 8 - 14 days), moderate (15 - 31 days) and extreme ( $\geq 31$ days) delays [13].

Treatment methods were classified into closed reduction, open reduction and internal fixation (ORIF) under general anesthesia (GA), and conservative management.

The data collected were analyzed by SPSS version 20 by using various descriptive statistical tools. Mean and standard deviation were calculated for quantitative variable like age, while frequency and percentage were calculated for qualitative variables like gender and site of fractures.

No institutional review board was available in our institution for such study. But the board was notified. Strict ethical compliance with human study was adhered to in this study.

\section{Results}

A total of 182 patients were involved and treated within the study period. The majority of patients were male $(72.0 \%)$, with a male to female ratio of 1:0.4. Most patients were between 31 and $40(34.1 \%)$ years of age, with the mean age for male being
$31.64 \pm 11.9$, and for female $31.47 \pm 12.3$, respectively; and the overall mean age is $31.54 \pm 12.1$. The least affected age group was 61years and above (Table 1).

Table 2 shows that RTA accounted for $73.1 \%$ of the injuries, which was the most common cause for maxillofacial injury followed by assault (19.2\%). Majority of injuries due to RTA were, as a result, of motorcycles accidents (33.6\%), followed by motor vehicle $(31.3 \%)$. More often the assault was inflicted by sticks and fist, only four cases of gunshot was recorded. Five cases $(2.8 \%)$ of sport injury were reported in our data.

Analysis revealed that the most common sites of fracture out of 226 sites were in the mandible $(62.8 \%)$, which was followed by fractures in the zygomatic bone $(15.5 \%)$, then the maxilla $(14.2 \%)$, the orbit $(3.1 \%)$, the nasal bone $(2.7 \%)$, and naso-orbito-etmoidal bone $(1.8 \%)$, respectively. The test of proportion for the site of injury showed that there was a statistically significantly higher frequency of fractures in the mandible compared to other sites $(\mathrm{P}=0.003)$ (Table 3$)$. Among the mandibular fracture sites, $28.2 \%$ affected the body of the mandible, $18.3 \%$ in the angle and $17.6 \%$ in the parasymphysial region. The least affected sites were the coronoid (1.4\%) and the ramus $(1.4 \%)$ (Table 4$)$.

Majority $(31.9 \%)$ of the studied patients presented within $24 \mathrm{~h}$ ( $\leq 1$ day), $26.9 \%$ under 1 week ( 2 - 7 days), 17.6\% presented within 2 weeks ( 8 - 14 days), $14.8 \%$ presented within 1 month but after 3 weeks (15 - 31 days). Only 16 (8.8\%) patients presented after 1 month $(>31$ days) (Table 5).

Out of the 182 patients, $68.1 \%$ were treated by close reduction. ORIF was performed on $22.5 \%$, and only $9.3 \%$ were conservatively managed (Fig. 1).

\section{Discussion}

Trauma is one of the major causes of death among people under 40 years of age [14]. The face, being the most prominent region of the human body, is therefore at significant risks of injury during traumatic events [15]. The epidemiology of maxillofacial injuries differs from one country to the other, and is constantly evolving [16]. Hence the need for a constant appraisal of these fractures injuries in order to keep abreast with recent developments and changing pattern of their manage- 
Table 2. Etiology of Maxillofacial Injuries

\begin{tabular}{|c|c|c|c|c|}
\hline & Male & Female & Total & $P$ value \\
\hline \multicolumn{5}{|l|}{ Type of injury } \\
\hline Road traffic accident & $93(68.9)$ & $40(85.1)$ & $133(73.1)$ & 0.042 \\
\hline Fall & $9(6.7)$ & $0(0.0)$ & $9(4.9)$ & 0.105 \\
\hline Sport & $5(3.7)$ & $0(0.0)$ & $5(2.8)$ & 0.557 \\
\hline Motorcycle & $33(34.4)$ & $12(31.6)$ & $45(33.6)$ & 0.442 \\
\hline Motor vehicle & $28(29.2)$ & $14(36.8)$ & $42(31.3)$ & 0.104 \\
\hline Pedestrian & $20(20.8)$ & $5(13.2)$ & $25(18.7)$ & 0.074 \\
\hline Tricycle & $8(8.3)$ & $7(18.4)$ & $15(11.2)$ & 0.043 \\
\hline
\end{tabular}

Table 3. Sites of Maxillofacial Fractures

\begin{tabular}{lllll}
\hline & Male & Female & Total & P value \\
\hline Site of maxillofacial fractures & & & & \\
Mandible & $101(62.0)$ & $41(65.1)$ & $142(62.8)$ & $0.003^{*}$ \\
Zygomatic complex & $30(18.4)$ & $5(7.9)$ & $35(15.5)$ & 0.043 \\
Maxilla & $26(16.0)$ & $6(9.5)$ & $32(14.2)$ & 0.139 \\
Nasal & $1(0.6)$ & $5(7.9)$ & $6(2.7)$ & 0.136 \\
NOE & $2(1.2)$ & $2(3.2)$ & $4(1.8)$ & 0.943 \\
Orbit & $3(1.8)$ & $4(6.3)$ & $7(3.1)$ & 0.432 \\
Anatomic site in maxilla & & & $8(25.0)$ & $0.012^{*}$ \\
Le Fort I & $8(30.8)$ & $0(0.0)$ & $13(40.6)$ & 0.084 \\
Le Fort II & $10(38.5)$ & $3(50.0)$ & $2(6.2)$ & 0.407 \\
Le Fort III & $2(7.7)$ & $0(0.0)$ & $3(28.1)$ & $0.037^{*}$ \\
Dentoalveolar & $6(23.1)$ & $3(50.0)$ & \\
\hline
\end{tabular}

NOE: naso-orbito-ethmoid. * $\mathrm{P}<0.05$.

Table 4. Distribution of Mandibular Fractures According to Anatomic Site

\begin{tabular}{lllll}
\hline Site of fracture & Male, $\mathbf{n}(\mathbf{\%})$ & Female, $\mathbf{n}(\mathbf{\%})$ & Total, $\mathbf{n}(\mathbf{\%})$ & P value \\
\hline Body & $26(25.7)$ & $14(34.1)$ & $40(28.2)$ & $0.047^{*}$ \\
Angle & $21(20.8)$ & $5(12.2)$ & $26(18.3)$ & $0.039^{*}$ \\
Parasymphysial & $19(19.8)$ & $6(14.6)$ & $25(17.6)$ & 0.391 \\
Condylar & $10(9.9)$ & $6(14.6)$ & $16(11.3)$ & 0.316 \\
Symphysial & $11(10.9)$ & $4(9.8)$ & $15(10.6)$ & 0.843 \\
Dentoalveolar & $12(11.9)$ & $4(9.8)$ & $16(11.3)$ & 0.951 \\
Coronoid & $0(0.0)$ & $2(4.9)$ & $2(1.4)$ & 0.715 \\
Ramus & $2(2.0)$ & $0(0.0)$ & $2(1.4)$ & 0.621 \\
Total & $101(100.0)$ & $41(100.0)$ & $142(100.0)$ & $0.032^{*}$ \\
\hline
\end{tabular}

${ }^{*} \mathrm{P}<0.05$. 
Table 5. Presentation for Treatment Following Injury

\begin{tabular}{lllll}
\hline Duration (days) & Male $(\mathbf{n}=\mathbf{1 3 1})$ & Female $(\mathbf{n}=\mathbf{5 1})$ & Total $(\mathbf{n}=\mathbf{1 8 2})$ & P value \\
\hline$\leq 1$ & $43(32.8)$ & $15(29.4)$ & $58(31.9)$ & 0.139 \\
$2-7$ & $35(26.7)$ & $14(27.4)$ & $49(26.9)$ \\
$8-14$ & $24(18.3)$ & $8(15.7)$ & $32(17.6)$ \\
$15-31$ & $21(16.0)$ & $6(11.8)$ & $27(14.8)$ \\
$>31$ & $8(6.1)$ & $8(15.7)$ & $16(8.8)$ \\
\hline
\end{tabular}

ment [17].

The most common age groups in our study were the third and fourth decades of life, which correlate with other studies $[5,12]$. This may be due to the participation of this age group in many outdoor activities and also their involvement in dangerous exercises and sports [15].

In our study, RTA was the most common cause of injuries, with majority resulting from motorcycle accident. The preference of some commuters for motorcycle which helps to overcome the heavy traffic within the city of Lagos despite its prohibition on the major roads and failure to use helmets while commuting is contributory. It was also observed that due to high rate of unemployment a large number of young men embark on the use of motorcycle to transport commuters from one place to the other without being conversant with the proper use of bikes or even traffic rules. Similar data have been reported by some authors from developing countries [18-20].

However, in many developed countries, there is a decreasing trend of RTA-related maxillofacial injuries, with interpersonal violence and assault becoming the leading etiological factors. This decrease has been attributed to strict enforcement of protective measures and various traffic legislations [21].

Assault ranked the second to RTA in the etiology of maxillofacial injuries as we observed, which is similar to most studies in Nigeria and other African studies [21]. However
Olasoji et al reported assault to be the main cause of facial fracture as $48 \%$ of their patients' sustained facial trauma as a result of assault-related injuries [22]. Our study revealed that $20.7 \%$ of the injured patients were men supporting evidence from other studies of the association between men and assault $[4,7]$. Interestingly, most of these fractures were caused by fist and sticks; there were only few cases of gunshots-related fractures. Conversely in the USA, owing to the easier accessibility to weapons, civilian violence has become more common [23].

Mandibular fractures had the highest frequency in the present study accounting for $62.8 \%$ of the total fractures. This is in agreement with most reports from Africa [21, 24] and Europe [4]. However, few reports from the Western world claim nasal bone fractures [25], and zygomatic complex fractures [26] occur more frequently. The mandible is believed to be more susceptible due to its mobility and lack of bony support like the well articulated midfacial bone [27]. The body of the mandible has been previously documented to be the most fractured site of the mandible [28, 29]. This was similarly observed in our study.

In the middle third, the zygomaticomaxillary complex is the most involved site due to its projection and multiple articulations with other facial skeletons making it very vulnerable to fractures on impact $[30,31]$.

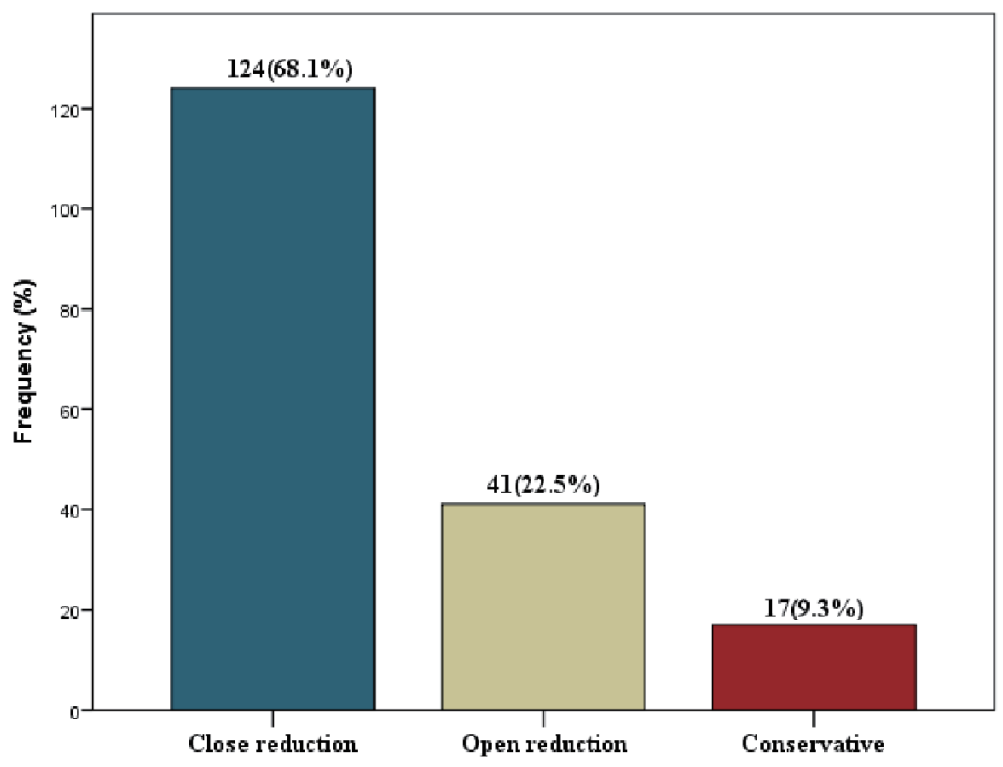

Figure 1. Treatment modalities for the maxillofacial fractures. 
Majority of the studied patients presented in the hospital within $24 \mathrm{~h}$. Ugboko et al [28] reported that one-third of their patients reported within this same period. The management of maxillofacial bony injuries remains controversial in terms of the timing and reconstruction techniques [23]. Delay in repair of maxillofacial injuries occasioned by late presentation sometimes is often unavoidable. There is however a large amount of evidence to support expedient fracture repair as a contributing factor in reducing postoperative complications [32].

Majority $(68.1 \%)$ of the patients in this study were treated with closed reduction. This is consistent with the studies of Jindwani et al [27], Ogunmuyiwa et al [21] and Olusanya et al [24]. However open reduction has been advocated to be the gold standard for the treatment of maxillofacial fractures [21]. The use of open reduction has resulted in improved oral hygiene, mouth opening, better speech and patient's earlier return to function [33]. However, despite these qualities, the cost of treatment has been a reason why only few patients were treated with open reduction in our center.

\section{Conclusions and recommendations}

RTA represented the major etiological factor of maxillofacial injuries, with young adult males as the main victims. The mandible remains the most affected bone of the facial skeleton. Closed reduction is the most common approach used due to the poor economic condition of most of the patients treated. It is therefore recommended that there should be improved implementation of traffic laws on motorist particularly the young population so as to curb reckless driving and over-speeding, organisation of motorcycle riders into association for proper training and certification, and provision of better roads and affordable health care by the various layers of government.

\section{Acknowledgments}

We would like to thank the Department of Health Information Management of the Lagos State University Teaching Hospital for helping to retrieve the record files of the patients in this study.

\section{Financial Disclosure}

There was no funding for this study.

\section{Conflict of Interest}

The authors declare that there is no conflict of interest regarding the publication of this paper.

\section{Informed Consent}

Not applicable.

\section{Author Contributions}

OA Adesina conceived and initiated the study. JC Wemambu designed the tables and figure. TO Opaleye contributed to the literature search and discussion. AY Salami did the data analysis.

\section{References}

1. Adebayo ET, Ajike OS, Adekeye EO. Analysis of the pattern of maxillofacial fractures in Kaduna, Nigeria. Br J Oral Maxillofac Surg. 2003;41(6):396-400.

2. Mohammad S, Firas A, Sukaina R, Ameen K. Trends in the pattern of facial fractures in different countries of the world. Int J Morphol. 2012;30(2):745-756.

3. Madubueze CC, Chukwu CO, Omoke NI, Oyakhilome OP, Ozo C. Road traffic injuries as seen in a Nigerian teaching hospital. Int Orthop. 2011;35(5):743-746.

4. Boffano P, Roccia F, Zavattero E, Dediol E, Uglesic V, Kovacic Z, Vesnaver A, et al. European Maxillofacial Trauma (EURMAT) project: a multicentre and prospective study. J Craniomaxillofac Surg. 2015;43(1):62-70.

5. Oruc M, Isik VM, Kankaya Y, Gursoy K, Sungur N, Aslan G, Kocer U. Analysis of Fractured Mandible Over Two Decades. J Craniofac Surg. 2016;27(6):1457-1461.

6. Adeyemo WL, Ladeinde AL, Ogunlewe MO, James O. Trends and characteristics of oral and maxillofacial injuries in Nigeria: a review of the literature. Head Face Med. 2005;1:7.

7. Lee K. Global trends in maxillofacial fractures. Craniomaxillofac Trauma Reconstr. 2012;5(4):213-222.

8. Shah SA, Bangash ZQ, Khan TU, Yunas M, Raza M, et al. The Pattern of Maxillofacial Trauma \& its Management. J Dent Oral Disord Ther. 2016;4(4):1-6.

9. Singaram M, G SV, Udhayakumar RK. Prevalence, pattern, etiology, and management of maxillofacial trauma in a developing country: a retrospective study. J Korean Assoc Oral Maxillofac Surg. 2016;42(4):174-181.

10. De Gioanni PP, Mazzeo R, Servadio F. [Sports activities and maxillofacial injuries. Current epidemiologic and clinical aspects relating to a series of 379 cases (19821998)]. Minerva Stomatol. 2000;49(1-2):21-26.

11. Fonseca R, Allen S, Awad M, Fonseca M. Initial assessment and intensive care of the trauma patient. In: Fonseca R, Barber D, Powers M, Frost D. Oral and maxillofacial trauma. Vol.1. St. Louis: Elsevier/Saunders; 2013. p. 4876.

12. Zarean P., Hosseinzadeh Namin A., Zarean P., Bashardoust N., Savabi Gh. Epidemiological assessment of oral and maxillofacial hard and soft tissue injuries: a oneyear survey in Amin hospital of Isfahan city, J Stoma 2017;70:160-170.

13. Porter M, Lownie M, Cleaton-Jones P. Maxillofacial injury: a retrospective analysis of time lapse between injury and treatment in a South African academic maxillofacial and oral surgery unit. S Afr J Surg. 2013;51(4):138-142.

14. Gassner R, Tuli T, Hachl O, Rudisch A, Ulmer H. Cranio- 
maxillofacial trauma: a 10 year review of 9,543 cases with 21,067 injuries. J Craniomaxillofac Surg. 2003;31(1):5161.

15. Van den Bergh B, Karagozoglu KH, Heymans MW, Forouzanfair T. Aetiology and incidence of maxillofacial trauma in Amsterdam: a retrospective analysis of 579 patients. Journal of Cranio-Maxillofacial Surgery. 2012;40(6):165-169.

16. Mijiti A, Ling W, Tuerdi M, Maimaiti A, Tuerxun J, Tao YZ, Moming A. Epidemiological analysis of maxillofacial fractures treated at a university hospital, Xinjiang, China: a 5-year retrospective study. Journal of Cranio Maxillofacial Surgery. 2014;42(3):227-233.

17. Rix L, Stevenson AR, Punnia-Moorthy A. An analysis of 80 cases of mandibular fractures treated with miniplate osteosynthesis. Int J Oral Maxillofac Surg. 1991;20(6):337341 .

18. Kamulegeya A, Lakor F, Kabenge K. Oral maxillofacial fractures seen at a Ugandan tertiary hospital: a six-month prospective study. Clinics (Sao Paulo). 2009;64(9):843848.

19. Umar KB, Shuja RA, Ahmad K, Mohammad TK, Abdus S. Occurrence and characteristics of maxillofacial injuriesA study. Pakistan Oral \& Dental Journal. 2010;30:57-61.

20. Pyungtanasup K. The epidemiology of mandibular fractures treated at Chiang Mai University Hospital: a review of 198 cases. J Med Assoc Thai. 2008;91(6):868-874.

21. Ogunmuyiwa SA, Gbolahan OO, Ayantunde AA, Odewabi AA. Patterns, severity, and management of maxillofacial injuries in a suburban South Western Nigeria tertiary center. Niger J Surg. 2015;21(1):38-42.

22. Olasoji HO, Tahir A, Arotiba GT. Changing picture of facial fractures in northern Nigeria. Br J Oral Maxillofac Surg. 2002;40(2):140-143.

23. Norris O, Mehra P, Salama A. Maxillofacial Gunshot Injuries at an Urban Level I Trauma Center-10-Year Analysis. J Oral Maxillofac Surg. 2015;73(8):1532-1539.

24. Olusanya AA, Adeleye AO, Aladelusi TO, Fasola AO. Updates on the epidemiology and pattern of traumatic maxillofacial injuries in a nigerian university teaching hospital: a 12-month prospective cohort in-hospital outcome study. Craniomaxillofac Trauma Reconstr. 2015;8(1):50-58.

25. Arslan ED, Solakoglu AG, Komut E, Kavalci C, Yilmaz F, Karakilic E, Durdu T, et al. Assessment of maxillofacial trauma in emergency department. World J Emerg Surg. 2014;9(1):13.

26. Dibaie A, Raissian S, Ghafarzadeh S. Evaluation of maxillofacial traumatic injuries of forensic medical centre of Ahwaz, Iran, in 2005. Pakistan Journal of Medical Sciences. 2009;25(1): 79-82.

27. Jindwani K, Markam HS, Paharia YK, Singh K. Maxillofacial fractures: etiology, incidence, pattern and treatment of maxillofacial injuries in a Government Medical College of Central India. J Adv Med Dent Scie Res. 2018;6(3):101-106.

28. Ugboko VI, Odusanya SA, Fagade OO. Maxillofacial fractures in a semi-urban Nigerian teaching hospital. A review of 442 cases. Int J Oral Maxillofac Surg. 1998;27(4):286-289.

29. Ajagbe HA, Daramola JO, Oluwasanmi JO. Civilian type facial injuries - a retrospective study of cases seen at the University college hospital, Ibadan. Niger Med J. 1977;7(4):432-437.

30. Schneider D, Kammerer PW, Schon G, Dinu C, Radloff S, Bschorer R. Etiology and injury patterns of maxillofacial fractures from the years 2010 to 2013 in MecklenburgWestern Pomerania, Germany: A retrospective study of 409 patients. J Craniomaxillofac Surg. 2015;43(10):19481951.

31. Mesgarzadeh AH, Shahamfar M, Azar SF, Shahanfar J. Analysis of the pattern of maxillofacial fractures in Noerth Western of Iran. A retrospective study. J Emerg Trauma Shock. 2011;4(1);48-52.

32. Radabaugh JP, Zhang P, Wang D, Lin PL, Shelton J, Liau JY, Cunningham LL, Jr., et al. Barriers to repair in maxillofacial trauma. JAMA Facial Plast Surg. 2016;18(3):177182.

33. Morkel JA. Cranio-maxillofacial surgery and rehabilitation and the University of the Western Cape. SADJ. 2009;64(10):448-449. 